\title{
Farmers Market Locations and Their Determinants: An Empirical Analysis in New England
}

\author{
Alessandro Bonanno, Joshua Berning, and \\ Hamideh Etemaadnia
}

\begin{abstract}
After a strong expansion across the United States, farmers markets' (FMs) growth rate has declined in spite of policymakers' interest in promoting them. In this study we model farmers' participation in FMs and investigate what market factors affect FMs' location using zip-code-level data for the New England states. Our results suggest that market size, education, presence of children in the household and SNAP participation lend to the establishment of FMs, more than income per se. Farming activities has a positive association with the likelihood of FMs, while proxies for establishment costs and the presence of traditional distribution channels may play a limiting role in their formation.
\end{abstract}

Key Words: entry, farmers markets, New England, short channel

In the United States, a farmers market (FM) is a common area where farmers gather on a recurring basis to sell a range of products including fresh fruits and vegetables, and other farm products, directly to consumers (Martinez et al. 2010). The USDA Agricultural Marketing Service reports that from 1994

\begin{abstract}
Alessandro Bonanno is an associate professor of agricultural economics in the Department of Agricultural and Resource Economics at Colorado State University. Joshua Berning is an associate professor in the Department of Agricultural and Applied Economics at the University of Georgia. Hamideh Etemaadnia is a Senior Transportation Modeler with C\&M Associates. Corresondence: Alessandro Bonanno = Associate Professor of Agricultural Economics Department of Agricultural and Resource Economics; Colorado State University; Clark Building, Room B327 - Fort Collins, CO 80524 . Phone: 970.491 .5543 . Email alessandro.bonanno@ colostate.edu. Joshua Berning " Associate Professor; Department of Agricultural and Applied Economics - University of Georgia, Conner Hall " 147 Cedar Street - Athens, GA 30602 " Phone: 706.542.0768 - Email jberning@uga.edu; Hamideh Etemaadnia = Senior Transportation Modeler C\&M Associates = Tollway Towers North - Suite 87015770 North Dallas Parkway Dallas = Texas 75248 - Tel: 214.245.5300 Ext. 428 -Email hetemadnia@candm-associates.com

The authors would like to thank Hualu Zheng for help with data collection, Stephan Goetz and Rebecca Cleary for comments on previous versions of the manuscript, participants at the 2013 AAEA \& CAES Joint Annual Meeting, 2014 NAREA Annual Meeting, and seminar participants at Wageningen University for discussions on early versions of this work. Funding from the Agricultural Experiment Station of Colorado State University and the University of Georgia is gratefully acknowledged. Last, we would like to thank the editor, Todd Schmidt, and two anonymous reviewers, for comments and suggestions that have improved the paper during the review process. All remaining errors, are, of course, ours.

The views expressed are the authors' and do not necessarily represent the policies or views of any sponsoring agencies.
\end{abstract}

Agricultural and Resource Economics Review 46/3 (December 2017) 479-506

(C) The Author(s) 2017. This is an Open Access article, distributed under the terms of the Creative

Commons Attribution licence (http://creativecommons.org/licenses/by/4.0/), which permits unrestricted re-use, distribution, and reproduction in any medium, provided the original work is 
to 2015 the number of FMs in the United States has increased from 1,755 units to 8,476 . However, growth rates have slowed in recent years, from 1.5 percent to 2.5 percent.

Several benefits have been associated with the presence of short food supply chains, of which FMs are an example. From the participant farmers' (i.e., vendors') standpoint, direct channels allow them to avoid intermediaries and retailers and, as a result, to realize a higher share of the channel's profits (La Trobe 2001). Besides internalizing higher margins, participating farmers can have direct access to consumers with higher willingness to pay for locally produced foods (Gilg and Battershill 1998). FMs can also give vendors greater ability to launch and test new products (Brown 2002, Brown and Miller 2008).

FMs are found to provide societal benefits including positive community-wide impacts such as human capital building (Brown 2002, Brown and Miller 2008), facilitation of social interaction, promotion and development of trust and social capital (Hunt 2007), and a stronger sense of connection between consumers and the local community (Gale 1997). For consumers, FMs may increase customer satisfaction due to freshness and quality of products (Govindasamy et al. 2002), and may lead to increased consumption of fruit and vegetables and other "wholesome" foods. A few authors also suggest that FMs can contribute to improved diets and a reduction in childhood obesity (Frieden, Dietz, and Collins 2010). To this point, Berning (2012) finds higher densities of FMs and community supported agriculture ${ }^{1}$ to be inversely related to individual weight outcomes in the United States, while Bimbo et al. (2015) find a negative correlation between FMs' presence and adults' BMI in Italy. More generally, Salois (2012) finds the presence of short food supply chains to have a negative association with obesity rates and diabetes' prevalence.

The rapid growth of FMs in the United States has been promoted by policymakers who aim to expand the sales of locally produced food and agricultural commodities (see Martinez et al. 2010, for a summary of federal, state and local policies supporting local food production) while also attempting to improve access to food for underserved individuals. The 2014 Farm Bill supports directly the development of more FMs via the direct marketing grants program of the Farmers Market Promotion Program (FMPP). Indirectly, the Local Food Promotion Program (LFPP) aims to strengthen the structure of local food supply chains. Furthermore, many FMs have adopted strategies targeting low-income consumers by accepting Electronic Benefit Transfer (EBT) from the Supplemental Nutrition Assistance Program (SNAP). A Congressional Research Service report indicates that 2,445 FMs and farmers were authorized to accept SNAP in 2011, and the redeemed benefits totaled $\$ 11.7$ million (Johnson, Alison and Cowan, 2013).

1 Community supported agriculture is a contractual agreement between a farm and a group of consumers who purchase a share of a farms' production in advance (Cone and Myhre 2000). 
These figures represent a 51 percent increase in authorizations and more than a 55 percent increase in redeemed benefits compared to 2010. As of July 2014, about two thirds of the states authorized farmers to accept cash value vouchers from the Women, Infants and Children (WIC) program through the Farmers Market Nutrition Program (FMNP). ${ }^{2}$

Given the increasing interest of policymakers and local planners in promoting FMs, and the potential benefits associated with them, it is both relevant and timely to evaluate the economic factors facilitating and supporting their development. The geographic dispersion of FMs shows higher numbers along the coasts, predominantly in proximity to highly populated areas in California, in the northeast, and surrounding the Great Lakes (Martinez et al. 2010). This can be attributable to the fact that, to be successful, FMs must attract both sufficient numbers of vendors and consumers to a single location. Thus, areas where more FMs exist can be found in easy to reach, populated areas, with a relatively high level of farming activities. At the same time, vendors face higher competition in areas with higher demand, which can be costly (Lohr et al. 2011). While less populous areas may not be current hot spots of growth for FMs, they could represent lower-cost options for producers if sufficient demand exists to support their economic viability.

Anecdotal evidence suggests that the continued expansion of FMs over the last few years may mask high failure rates. ${ }^{3}$ Several factors are found to be affecting the likelihood of FMs market failures (Stephenson, Lev, and Brewer 2008). While areas most suited for supporting one or more FMs may already be saturated, areas less suited for supporting FMs, either because of limited demand or infrastructure, may be those that remain unserved, making policy efforts to promote FM expansion harder to be implemented. ${ }^{4}$ While academic research has attempted to characterize FM shoppers and their motivations for patronizing these outlets (e.g., Wolf, Spittler, and Ahern 2005, Zepeda 2009, Pascucci et al. 2011, Gumirakiza, Curtis, and Bosworth 2014) and to assess the factors that affect the performance of their vendors (e.g., Schmidt and Gómez 2011, Varner and Otto 2008), with the exception of Lohr et al. (2011) and Singleton, Sen, and Affuso (2015), little is known of the market forces driving FM formation.

In this article we assess the demand- and supply-side conditions that facilitate FM creation. To achieve this objective we create a theoretical model of a farmer's decision to engage in an FM and determine an expression for the

\footnotetext{
2 Other activities that increase the demand for products sold at FMs are the Senior Farmers' Market Nutrition Program which provides coupons to low-income seniors, which can be exchanged for eligible foods at FMs and other direct-to-consumer types of outlets.

3 For example, they report that the Oregon State University Extension Service found that of the 62 FMs that opened in Oregon from 1998-2005, more than 50 percent (32) had closed.

4 Parallel research on food retailers in the United States suggests that not every geographic location can support (large) food retailer locations because of lack of demand or paucity of infrastructure (Bonanno 2012, Bonanno, Cleary, Chenarides-Hall, and Goetz 2016).
} 
equilibrium number of farmers willing to participate. Based on this result, we parameterize different specifications of a reduced-form empirical model to estimate how specific market factors affect the probability of observing one or two or more FMs in a given area.

We choose the New England states as a case study for two reasons. First, while the northeast is one of the areas showing the highest prevalence of FMs (see Martinez et al. 2010 pg. 8), in the year prior to our sample year (2012) New England presented one of the largest areas of growth in FMs, well above the national rates (14.4 percent, second only to the mid-Atlantic, 15.8 percent) (USDA, 2012). Second, as illustrated in more detail in the data section, while there is a relatively high variation in the number of FMs across zip codes in New England, the size of each zip code (in terms of square miles) is less heterogeneous in these states compared to other parts of the nation, which can reduce unobserved heterogeneity bias.

Our results indicate that market size, presence of children in the household, a more educated and younger population, and a higher percentage of individuals in SNAP, are more likely to foster the location of FMs, as well as a higher pool of potential participant vendors. Also, the opportunity cost of selling area, used as a proxy for establishments' costs, is associated with a lower probability of observing more FMs, and while the presence of alternative distribution channels (that is, fruit and vegetable wholesalers) is inversely related to the likelihood of observing FMs, grocery stores seem to act as complements.

\section{A Model for Farmers Market Formation and Location}

Assume that, in a given geographic market, there are $M$ farmers who decide through which marketing channel to sell their product, the FM channel $(a)$, the traditional retail channel $(b)$ or both. The total market size for a given geographic area is $S$. Consumers can shop in both channels: a fraction $\lambda$ prefers the FM marketing channel $\left(S_{a}=\lambda S\right)$, while the rest prefer traditional channels or $S_{b}=(1-\lambda) S$. Therefore, $S=S_{a}+S_{b}=\lambda S+(1-\lambda) S$.

Consider the $i$ th farmer $(i=1$ to $M)$, whose potential sales from the FM channel $\left(S_{i a}\right)$ and traditional channel $\left(S_{i b}\right)$ are determined by the number of participants in each channel, or $S_{i a}=\frac{S_{a}}{m_{a}}=\frac{\lambda S}{m_{a}}$ and $S_{i b}=\frac{S_{b}}{m_{b}}=\frac{(1-\lambda) S}{m_{b}}$, where $m_{a}$ and $m_{b}$ are homogenous farms participating in the FM channel and in the traditional channel, respectively. Each channel price $(P)$ is determined by the market and the average variable cost $(A V C)$ for producing and selling products in each channel is assumed constant. The per-unit margin for products sold through each channel $j$ is $\theta_{j} \equiv\left(P_{j}-A V C_{j}\right)$ where $j=[a, b]$.

To participate in the FM channel, each farmer pays a fee $(F)$ that is determined by establishment costs $(E)$, assumed to be evenly distributed across participants or $F=E / m_{a}$. The establishment costs include selling area rental expenses, and utility costs, advertising, and marketing for the FM and any 
other management and maintenance costs required to create, maintain, and organize the $\mathrm{FM}^{5}{ }^{5}$

In the simplest case (Scenario 1), farmers participate in only one of the channels. This implies that $M=m_{a}+m_{b}$ and that $S_{i a}=\frac{\lambda S}{m_{a}} \quad$ and $S_{i b}=\frac{(1-\lambda) S}{M-m_{a}}$. Similar to Sexton's (1986) work on cooperatives, participating in an FM is desirable for a farmer if:

$$
\psi_{i}=\pi_{i a}-\pi_{i b}=\theta_{a} \frac{\lambda S}{m_{a}}-\theta_{b} \frac{(1-\lambda) S}{M-m_{a}}-F \geq 0
$$

When equation (1) is an equality, a farmer will be indifferent to participating in an FM or in the traditional channels. Manipulating this expression for the indifferent farmer, one can obtain the limiting number of farms participating in the FM channel:

$$
m_{a}^{*}=M \frac{\theta_{a} \lambda S-E}{\theta_{b}(1-\lambda) S+\theta_{a} \lambda S-E}(\text { Scenario } 1)
$$

If equation (2) is continuous, it is easy to verify that participation decreases with establishment costs, although at declining rates $\left(\frac{\partial m_{a}^{*}}{\partial E}<0, \frac{\partial^{2} m_{a}^{*}}{\partial E^{2}}>0\right)$. Participation also decreases with the margin of the traditional channel at a decreasing rate $\left(\frac{\partial m_{a}^{*}}{\partial \theta_{b}}<0, \frac{\partial^{2} m_{a}^{*}}{\partial \theta_{b}^{2}}>0\right)$ and increases at a decreasing rate with the margin for the FM channel $\left(\frac{\partial m_{a}^{*}}{\partial \theta_{a}}>0, \frac{\partial^{2} m_{a}^{*}}{\partial \theta_{a}^{2}}<0\right)$. Participation increases at a decreasing rate with the share of consumers preferring the short channel $\left(\frac{\partial m_{a}^{*}}{\partial \lambda}>0, \frac{\partial^{2} m_{a}^{*}}{\partial \lambda^{2}}<0\right)$ and increases linearly with the total number of farmers $\left(\frac{\partial m_{a}^{*}}{\partial M}>0, \frac{\partial^{2} m_{a}^{*}}{\partial M^{2}}=0\right)$. Finally, participation increases at a decreasing rate with the total market size $\left(\frac{\partial m_{a}^{*}}{\partial S}>0, \frac{\partial^{2} m_{a}^{*}}{\partial S^{2}}<0\right)$.

\footnotetext{
5 We assume managerial costs are covered by fixed costs encumbered by participating farms (participation fee). Higher establishment fixed costs, and therefore managerial costs, are indicated as important to ensure the functioning of an FM. Stephenson, Le and Brewer (2008) point out that factors such as low administrative revenue, low pay for the FM manager, and high manager turnover are associated with FM failure.
} 
Alternatively, farmers have the ability to participate in both channels at once (Scenario 2). Farmers may do this for one of two reasons. First, in joining both channels, farmers can cater to different consumer types and spread production risk; these farmers may produce higher-quality products and will likely benefit the most from the FM channel. ${ }^{6}$ Second, farmers selling primarily in traditional channels may treat the FM channel as an outlet for their excess supply, as they may see FMs as seasonal and less consistent than traditional channels. In both cases, farmers' sales to each channel are determined by participation: in this case the decision to enter the FM channel only requires that variable profits exceed participation costs, or $\theta_{a} \lambda S \geq E$ (in this second scenario, $m_{a}$ represents the number of farmers participating in the FM channel plus those participating in both channels). That is, a farmer will be more likely to participate in the FM channel if per-unit margin or consumer demand for FMs increases, or if the establishment costs decrease.

Let us consider now the creation of an FM. For the equilibrium number of FMs $(N)$ in a given area to be strictly positive, enough farmers must be willing to participate. Thus, for an FM to exist, at least one farmer must find joining the

FM channel profitable. In Scenario 1, participating in an FM requires the establishment fee to be bounded as $0<E<\theta_{a} \lambda S-\frac{(1-\lambda) S \theta_{b}}{M-1}$ (because $E$ is non-negative) while in Scenario 2 the condition to be satisfied is $0<E<\theta_{a}$ $\lambda S$. Thus, for the same levels of $\theta_{a}, \lambda$ and $S$, joining an FM can still be profitable at higher participation fees in markets where farmers can join both channels (Scenario 2), than in those where participation in one channel is exclusive (Scenario 1). If program participation fees are reduced (that is, as $E \rightarrow 0$ ), the maximum number of participating farmers is bounded by $m_{a} \in$ $\left(1, M \frac{\theta_{a} \lambda S}{\theta_{a} \lambda S+(1-\lambda) S \theta_{b}}\right)$ in Scenario 1 and by $M$ in Scenario 2 . Thus, factors supporting the adoption of two channels (presence of alternative distribution systems, etc.) may create conditions more conducive to FM creation. These two results imply that it is more likely to observe a higher participation in Scenario 2 than in Scenario 1, or in other words, factors facilitating the adoption of two channels can foster higher $N$.

We assume that, once a minimum participation threshold is reached, there is a positive relationship between the number of farmers / vendors participating in the FM channel $m_{a}^{*}$ and the number of FMs $N$. Let us consider now $N^{*}$, a realization of $N$. Define $\bar{m}_{a\left(N^{*}\right)}$ as the minimum number of participating

\footnotetext{
6 This sub scenario is consistent with the Schmidt and Gómez (2011) finding that farmers selling a larger share of their products at FMs are more satisfied with their performance adopting the FM channel.
} 
farmers necessary for the probability of observing at least $N^{*} \mathrm{FMs}$ to be nonzero. For any $m_{a}^{*}$ strictly greater than $\bar{m}_{a\left(N^{*}\right)}$ one has:

$$
\operatorname{Pr}\left[N^{*}>0 \mid m_{a}^{*}\left(\lambda, S, \theta_{a}, \theta_{b}, E, M\right)>\bar{m}_{a\left(N^{*}\right)}\right]>0
$$

Equation (3) indicates that even if there are some farmers wanting to join an FM, there need to be enough of them to support $N^{*}$ FMs. Generalizing, the number of FMs will be limited by the number of participating farmers such that:

$$
\operatorname{Pr}\left[N^{*}+1 \mid \bar{m}_{a\left(N^{*}+1\right)}>m_{a}^{*}(.) \geq \bar{m}_{a\left(N^{*}\right)}\right]=0,
$$

where $\bar{m}_{a\left(N^{*}+1\right)}$ is the minimum number of FMs required to establish $N^{*}+1$ FMs. In other words, if there are fewer than $\bar{m}_{a\left(N^{*}+1\right)}$ participant farmers it is not possible for $N^{*}+1$ farmers markets to form ${ }^{7}$. For any non-zero values of $m_{a}^{*}($.$) satisfying conditions (3) and (4), there will be an equilibrium number$ of FMs equal to $N^{*}$. Intuitively, as a farmer-participation threshold is crossed, the probability that an additional FM is formed will increase. As participation grows, new thresholds are reached, and the probability of observing additional FMs increases.

The number of FM participants, as well as participation thresholds, are not observed, whereas the number of FMs and market characteristics influencing participation are. Thus, we treat participants' numbers as a latent variable and recover the effect of different market characteristics by estimating the probability of observing a given number of FMs $N^{*}$. To that end, we parameterize an expression for $N^{*}$ as a function of the factors affecting FM participation and estimate the link between the number of observed FMs and market characteristics determining participation. The probability of observing an area with at least $N=N^{*} \mathrm{FMs}$ is

$$
\operatorname{Pr}\left(N^{*}>N\right)=1-\Phi\left(m_{a\left(N^{*}\right)}\right)
$$

where $\Phi($.$) is the standard normal cumulative density function and m_{a\left(N^{*}\right)}=$ $m_{a}^{*}\left(\lambda, S, \theta_{a}, \theta_{b}, E, M\right)+\varepsilon$ represents the number of participating farmers satisfying the condition $m_{a}^{*}>\bar{m}_{a\left(N^{*}\right)}$, while the probability of observing an area with exactly $N^{*}$ FMs is

\footnotetext{
7 This can become more complex in practice as farmers can participate in multiple FMs. Further, this assumes that all FMs have the same level of quality and output. Conceptually, one could normalize heterogeneous FMs by quality or quantity and calculate the number of equivalent farmers required to establish an FM with some probability.
} 


$$
\operatorname{Pr}\left(N^{*} \leq N<N^{*}+1\right)=\Phi\left(m_{a\left(N^{*}+1\right)}\right)-\Phi\left(m_{a\left(N^{*}\right)}\right) .
$$

For simplicity, we assume $m_{a}^{*}\left(\lambda, S, \theta_{a}, \theta_{b}, E, M\right)=\boldsymbol{X}^{\prime} \boldsymbol{\beta}$, where $\boldsymbol{X}$ is a vector of covariates including elements that characterize the different factors affecting market participation, and $\boldsymbol{\beta}$ is a conformable vector of coefficients capturing the relationship between the different covariates and market participation. Given the assumptions illustrated above, estimates of the vector $\boldsymbol{\beta}$ are obtained using an ordered probit estimator. ${ }^{8}$

\section{Data}

We estimate the parameters of our model using a zip-code-level database encompassing the six New England states, assembled from different sources. Our data were collected in the spring of 2013 and represent a single crosssection. We acquired data on FMs' zip code location from LocalHarvest, Inc. (localharvest.org), which provides a nationwide registry of FMs free of charge. In addition, LocalHarvest indicates the last time an FM's information was updated. While a large share of FMs update their LocalHarvest site regularly, for those that have not updated their site in the last two years, we determined whether the FM was still in operation using State-level Department of Agriculture listings of FMs and internet searches. ${ }^{9}$ The initial data set is comprised of 1,833 zip codes. In New England, seventy seven percent of the zip codes do not have an FM, nineteen percent have at least one, and the remaining four percent has two or more FMs (Table 1).

We use total population in each zip code from the 2011 American Community Survey to characterize market size $(S)$. Figure 1 shows the geographic distribution of FMs location (left panel) and population (right panel) in New England's zip codes. This map shows that FMs seem mostly located along the coasts and in proximity to large urbanized areas, and that areas with higher populations are more attractive as the location of one or more FMs.

Variables capturing factors affecting consumer preferences for FMs (i.e. $\lambda$ ) also come from the American Community Survey. First, we control for the share of household with children, median age in the zip code, as well as the

8 It should be noted that we assume away heterogeneity in FMs and the presence of any regulation limiting FMs' creation. These assumptions are similar to those used by Bresnahan and Reiss (1991) in their empirical analysis of the competitive environment and market thresholds necessary to support one or more service establishments in a given area. To appropriately model heterogeneity in entrants, one should use more complex approaches, such as those by Berry (1992), Mazzeo (2002), or Seim (2006). Schaumans and Verboven (2008) relax the free-entry assumption and consider the presence of regulation restricting entry.

9 There is concern about whether or not the FMs registered on LocalHarvest are representative of the total number for each state. Because registration is voluntary, LocalHarvest provides free advertising, which should create a strong incentive to register. Further, even the USDA referenced LocalHarvest on their own website as a source for locating FMs. 
Table 1. Frequency of FMs Within Zip Codes

\begin{tabular}{cccc}
\hline Number of FMs & Freq. & Percent & Cum. \\
\hline 0 & 1,409 & 76.87 & 76.87 \\
1 & 355 & 19.37 & 96.24 \\
2 & 55 & 3.00 & 99.24 \\
3 & 9 & 0.49 & 99.73 \\
4 & 3 & 0.16 & 99.89 \\
5 & 2 & 0.11 & 100 \\
Total & $\mathbf{1 , 8 3 3}$ & $\mathbf{1 0 0}$ & \\
\hline
\end{tabular}

average household size in the zip code, as the size of the household affects the likelihood of shopping at FMs (Gumirakiza, Curtis, and Bosworth 2014). As ethnicity seems to be correlated with FMs' location (Singleton, Sen, and Affuso 2015), we control for the share of nonwhite individuals in the zip code. We also include the share of individuals with bachelor's degrees or higher as other studies find that having completed postgraduate work is a likely feature of FMs' shoppers (e.g., Wolf, Spittler, and Ahern, 2005). We control for the percentage of SNAP participants (county-level, from the Small Area Income and Poverty Estimates database) as SNAP benefits may allow
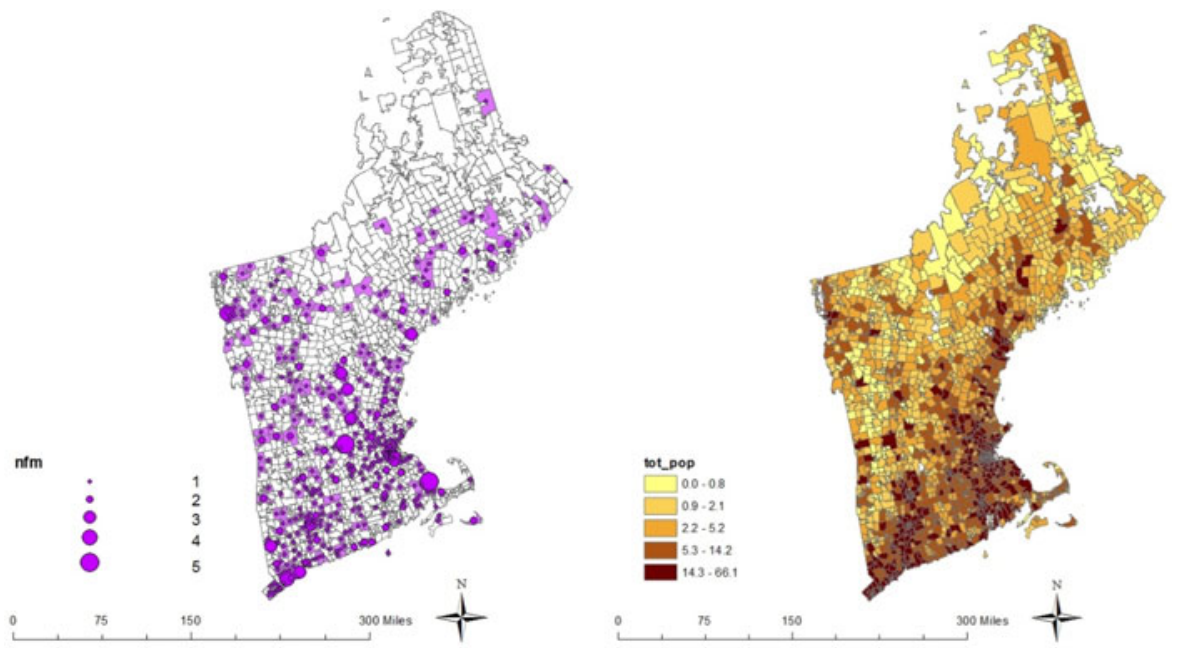

Figure 1. Zip-Code-Level Location of FMs (Left Panel) and Total Population (tot_pop) in New England

Source: Authors' Elaboration of Data Collected from Local Harvest (Left Panel) and American Community Survey (2011) (Right Panel). 
more households to participate in the market, given the higher acceptance of EBT at FMs. Last, we control for median income, even though the evidence that consumers' income affects FMs patronage is mixed. ${ }^{10}$

To capture $M$, the total pool of potential participating farmers, we used zipcode-level data from the 2007 Census of Agriculture. For each zip code we calculated the total number of fruit and vegetable operations and identify zip codes with no farms. According to our theoretical model, we expect that as the number of fruit and vegetable operations increases, the likelihood of an FM being established will increase as well. Alternatively, zip codes with no farms will be less likely to have FMs. Figure 2 presents a map of fruit and tree-nut farms as well as vegetable farms (including seeds and transplants) along with the number of FMs. As expected, the number of FMs seems to be higher in areas where more farming activities occur.

To obtain proxies for FM establishment costs $(E)$ we gather information on housing density and business establishments, assuming that locations with higher building costs will have a higher opportunity cost of land, resulting in higher establishment fees. Data on per-capita housing units were collected from the 2011 American Community Survey, while the location of business establishments came from the County Business Patterns database of the U.S. Bureau of Labor Statistics. We expect per-capita housing units to be directly related to establishment fees, and therefore to affect FMs at a negative but declining rate. As for establishment counts, we calculated the number (in hundreds) of small establishments (fewer than twenty employees) and medium/large establishments (greater than twenty employees) belonging to all NAICS codes, divided by total land in a zip code. As these represent different physical capital requirements, we expect the former to be negatively related to establishment fees, while the latter to be directly related to them.

We do not have data to measure channel mark-ups directly $\left(\theta_{a}\right.$ and $\left.\theta_{b}\right)$. We used the number of fruit and vegetable wholesalers as a proxy for the availability of traditional market channels for farmers, which will likely compete with direct-to-consumer distribution methods and affect the relative profitability of indirect channel sales over the direct one. We collected the number of establishments belonging to fresh fruit and vegetable wholesalers (NAICS 424480) from the 2010 Census. We expect this variable to affect negatively the probability of observing more FMs, although at a declining rate (consistent with $\theta_{b}$ effect in our theoretical model). Last, we control for the zip-code-level number of grocery stores (NAICS 45110 establishments from the 2010 Census). This variable may affect the formation of FMs via two

\footnotetext{
10 Some studies find a direct relationship between consumer income and vendor performance (e.g., Morgan and Alipoe, 2001, Wagner and Otto, 2008); however, other studies find no difference in the income levels of individuals who shop in FMs and those who do not (Wolf, Spittler, and Ahern, 2005, Zepeda et al., 2009). Singleton, Sen, and Affuso (2015) found that income can be correlated to FMs' presence in urban areas but not in rural areas.
} 


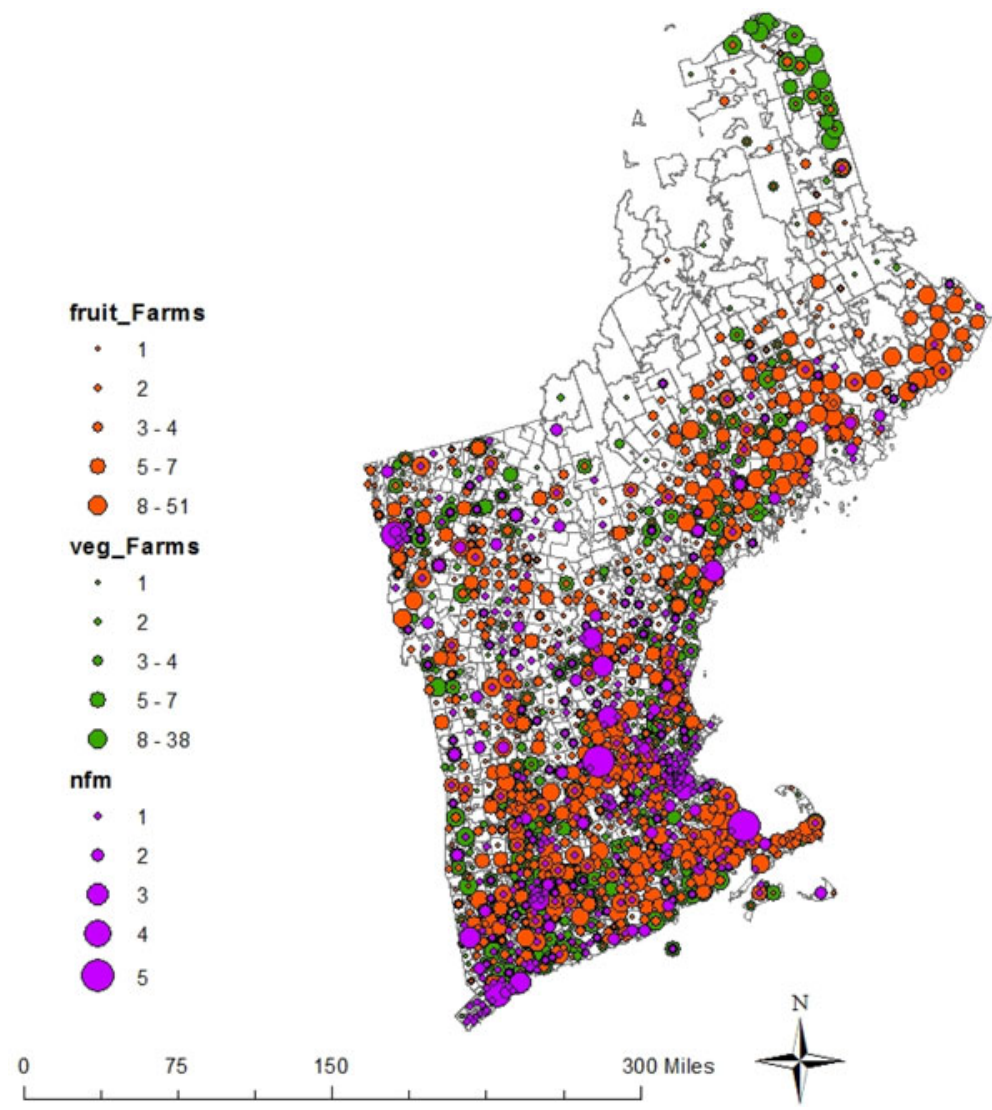

Figure 2. Location and Number of Farms with Fruits and Nuts (fruit_Farms), Vegetables (veg_Farms), and FMs (nfm) in New England

Source: Authors' Elaboration of Census of Agriculture Data (2007)

different mechanisms. On the one hand, grocery stores may compete with FMs as a substitute, leading to lower profit margins for farmers participating in FMs and consequently a lower probability of FMs being established. On the other hand, previous research has shown grocery stores may complement FMs, therefore showing a positive association with FMs (Morgan and Alipoe 2001, Singleton, Sen, and Affuso 2015).

Summary statistics of the variables discussed above are presented in Table 2. To provide a descriptive assessment of our covariates and the presence of FMs, we present averages of our variables conditional on the different number of FMs (Table 3). Given the small number of zip codes with 3 or more FMs, conditional averages are obtained for zip codes with $0,1,2$ and 3 or more FMs. Total population tends to be larger in areas with more FMs, supporting the hypothesis that the size of a market is a significant driver of FMs. As for 
Table 2. Summary Statistics

\begin{tabular}{|c|c|c|c|c|c|c|}
\hline $\begin{array}{l}\text { Group of } \\
\text { variables }\end{array}$ & Variable & N obs & Mean & St Dev & Min & Max \\
\hline & NFM & 1833 & 0.28 & 0.58 & 0 & 5 \\
\hline \multicolumn{7}{|c|}{ Market Size $(S)$} \\
\hline & Population (000s) & 1833 & 7.86 & 10.39 & 0 & 66.13 \\
\hline \multicolumn{7}{|c|}{ Taste Heterogeneity $(\lambda)$} \\
\hline & Household w/children (\%) & 1798 & 40.91 & 12.91 & 0 & 100 \\
\hline & Non-white (\%) & 1816 & 7.86 & 12.02 & 0 & 93.10 \\
\hline & Household size & 1801 & 2.44 & 0.35 & 1.16 & 5.53 \\
\hline & SNAP participation $\%$ & 1807 & 8.83 & 9.18 & 0 & 100 \\
\hline & Median age & 1808 & 43.20 & 7.55 & 13.50 & 81.50 \\
\hline & Median income $(0,000 s)$ & 1784 & 6.43 & 2.68 & 0.94 & 25 \\
\hline & High school grads (\%) & 1814 & 30.71 & 12.34 & 0 & 100 \\
\hline & $\begin{array}{l}\text { Bachelor or higher } \\
\text { degree }(\%)\end{array}$ & 1814 & 33.39 & 17.95 & 0 & 100 \\
\hline \multicolumn{7}{|c|}{ Number of Farms $(M)$} \\
\hline & $\begin{array}{l}\text { Fruit \& vegetables } \\
\text { operations }\end{array}$ & 1833 & 4.05 & 5.74 & 0 & 55 \\
\hline & No farms & 1833 & 0.14 & 0.34 & 0 & 1 \\
\hline \multicolumn{7}{|c|}{ Establishment Cost (E) } \\
\hline & Housing density & 1833 & 0.61 & 1.93 & 0 & 46.90 \\
\hline & $\begin{array}{l}\text { Small } \\
\quad \text { establishments/sq mile }\end{array}$ & 1833 & 0.50 & 3.10 & 0 & 72 \\
\hline & $\begin{array}{l}\text { Med-Large } \\
\quad \text { establishments/sq mile }\end{array}$ & 1833 & 0.10 & 0.83 & 0 & 20.86 \\
\hline \multicolumn{7}{|c|}{ Channel Margins $\left(\theta_{a}, \theta_{b}\right)$} \\
\hline & Fruit \& veg wholesalers & 1833 & 0.12 & 1.10 & 0 & 41 \\
\hline & Grocery stores & 1833 & 1.68 & 2.62 & 0 & 24 \\
\hline
\end{tabular}

the socioeconomic characteristics, the values in Table 3 indicate that one is more likely to observe a larger number of FMs in areas characterized by a more educated population and with a higher share of households with children. Median income and population age do not seem to exhibit any particular pattern, while areas with more FMs seem to have a higher share of SNAP participants. As expected, the average number of fruit and vegetable farms is larger in areas with more FMs, while absence of farms does not seem to be related to FM presence. Regarding supply-side variables, greater housing density and density of small establishments seem to be correlated with a higher presence of FMs, while no pattern emerges with the presence 
Table 3. Summary Statistics for Zip Codes with a Specific Number of FMs

\begin{tabular}{|c|c|c|c|c|c|}
\hline \multirow[b]{2}{*}{ Group of variables } & \multirow[b]{2}{*}{ Variable } & \multicolumn{4}{|c|}{ Number of FMs } \\
\hline & & $\mathbf{0}$ & 1 & 2 & $\geq 3$ \\
\hline \multicolumn{6}{|l|}{ Market Size $(S)$} \\
\hline & Population (000s) & 5.68 & 14.31 & 15.86 & 31.59 \\
\hline \multicolumn{6}{|l|}{ Taste Heterogeneity $(\lambda)$} \\
\hline & Household w/children (\%) & 39.95 & 43.97 & 43.39 & 47.71 \\
\hline & Non-white (\%) & 6.59 & 11.09 & 15.64 & 21.34 \\
\hline & SNAP participation $\%$ & 8.73 & 8.73 & 11.18 & 12.34 \\
\hline & Household size & 2.44 & 2.45 & 2.33 & 2.48 \\
\hline & Median age & 43.90 & 41.33 & 39.22 & 36.99 \\
\hline & Median income $(0,000 \mathrm{~s})$ & 6.31 & 6.98 & 5.59 & 6.78 \\
\hline & High school grads (\%) & 31.74 & 27.44 & 27.19 & 24.56 \\
\hline & Bachelor or higher degree grads (\%) & 31.94 & 38.23 & 37.17 & 40.01 \\
\hline \multicolumn{6}{|l|}{ Number of Farms $(M)$} \\
\hline & Fruit \& vegetables operations & 3.61 & 5.49 & 5.05 & 8.00 \\
\hline & No farms & 0.15 & 0.10 & 0.15 & 0.14 \\
\hline \multicolumn{6}{|l|}{ Establishment Cost $(E)$} \\
\hline & Housing density & 0.44 & 1.07 & 1.56 & 1.90 \\
\hline & Small establishments/sq mile & 0.38 & 0.82 & 1.18 & 1.21 \\
\hline & Med-Large establishments/sq mile & 0.08 & 0.19 & 0.24 & 0.21 \\
\hline \multicolumn{6}{|l|}{ Channel Margins $\left(\theta_{a}, \theta_{b}\right)$} \\
\hline & Fruit \& veg wholesalers & 0.08 & 0.27 & 0.18 & 0.29 \\
\hline & Grocery stores & 1.13 & 3.08 & 4.75 & 8.71 \\
\hline
\end{tabular}


of medium/large establishments. A larger number of fruit and vegetable wholesalers seems to exist in areas with a positive number of FMs, potentially due to the higher presence of fruit and vegetable farms. There appears to be a positive correlation between FMs and the number of grocery stores, likely because direct-to-consumers farm products and grocery stores may act as complements.

\section{Estimation and model specification}

The dependent variable in the estimation is the number of FMs in a zip code. Given the small number of zip codes with three or more FMs, we opted to use the following categorical variable in place of the actual number of FMs:

$$
F M(12)=\left\{\begin{array}{l}
0 \text { if } N F M=0 \\
1 \text { if } N F M=1 \\
2 \text { if } N F M \geq 2
\end{array}\right.
$$

Where all zip codes with two or more FMs are treated the same. ${ }^{11}$

To test whether the explanatory variables affect the probability of observing more FMs in a way consistent with our theoretical model, our model specifications include quadratic terms of some of the explanatory variables. Consistent with equation (2), the only two variables that enter all models specifications linearly are the number of fruit and vegetable farms and the indicator variable for absence of farms.

Given the two proxies for establishment cost (housing density and small and medium/large establishment densities), we specify three versions of the model: one including housing density (Model 1 ), a second including establishment densities (Model 2), and a third including both measures (Model 3). After preliminary exploration of the results, we noticed that the coefficients associated with the quadratic terms of some of the demographic variables (household size, share of individuals with a bachelor's degree or higher, median age, and median income) were not statistically different than zero across model specifications. Thus, we estimated three additional model specifications (Models 4, 5, and 6) as counterparts to Models 1, 2 and 3, where quadratic terms of these variables were excluded, to avoid over fitting.

11 Using FM(12) as the dependent variable in place of the number of FMs, reduced estimation issues arising from having a very small number of zip codes with more than two FMs in our data. We estimated models with the actual number of FMs as the dependent variable using two different approaches: negative binomial and Tobit estimation. In the first case, the over dispersion parameter was not statistically different than 0 , indicating that the data support a constantvariance process. The model was then estimated using a Poisson model. The estimated coefficients of the Poisson model, as well as the Tobit estimates (omitted for brevity and available upon request), are qualitatively similar to those discussed in the main text. 
Data manipulation and estimation were performed using STATA v. 13. Due to missing observations, the final sample size used for the estimation was 1,783. The different specifications of the model were estimated using a maximum likelihood (ML) ordered probit (OP) estimator, ${ }^{12}$ and model selection performed using the Akaike Information Criterion (AIC) and the Bayesian Information Criterion (BIC), which penalizes less parsimonious specifications.

\section{Results}

As the OP results reported in Table 4 show, our estimates are fairly consistent across model specifications. Based on both AIC and BIC, the model specifications where the quadratic terms for some of the demographic variables are excluded (Models 4, 5, and 6) outperform those that include them (Models 1, 2, and 3). Because Models 4 and 6 show the lowest BIC and AIC, the discussion that follows will focus primarily on the results of those models.

Considering the cross-sectional nature of our data, these models fit the data relatively well, with a pseudo R-squared of roughly 0.2 . Across all models specifications, we find that as population increases so does the number of FMs, although at a declining rate. This is consistent with the predictions of our theoretical model. This result suggests that participation and the probability of observing more FMs is more likely in areas with larger market size. However, as will be discussed in more detail below, the relationship between market size and the probability of observing a positive number of FMs tends to taper off, as other factors in the market may play a role in limiting farmers' participation.

With regard to consumer taste for the FM channel $(\lambda)$, we find some support for our theoretical model. Consistent with our expectations, participation is directly related (at a declining rate) to the share of households with children. Household size, median age, and the share of individuals with a bachelor's degree or higher have a statistically significant and positive association with the probability of observing a positive number of FMs in models 4, 5 and 6. Higher education levels, as well as smaller households, with more children and a younger population, seem to foster expansion of FMs. This is in line with previous literature which reports a younger, more educated consumer base for FMs (e.g., Wolf, Spittler, and Ahern 2005). We also find a positive relationship between share of population in SNAP and participation, although at a declining rate. Although this result may indicate that including EBT redemption at FMs increases patronage and creates additional demand for

\footnotetext{
12 ML OP estimates are valid only if the data satisfy the proportional odds property. Furthermore, as we use a cross-sectional zip-code-level data base, the presence of spatial correlation may affect our results. In the "Additional Estimates and Robustness Checks" section we examine whether relaxing the proportional odds assumption or allowing for spatial autocorrelation of the error terms affects our results.
} 
Table 4. Estimation Results of Ordered Probit Model; Dependent Variable FM (12)

\begin{tabular}{|c|c|c|c|c|c|c|c|}
\hline & Variable & Model 1 & Model 2 & Model 3 & Model 4 & Model 5 & Model 6 \\
\hline \multirow{4}{*}{$\begin{array}{l}\text { Market } \\
\text { Size (S) }\end{array}$} & Pop (000's) & $0.0492^{* * *}$ & $0.0492^{* * *}$ & $0.0550^{* * *}$ & $0.0477^{* * *}$ & $0.0483^{* * *}$ & $0.0535^{* * *}$ \\
\hline & & $(0.0127)$ & $(0.0130)$ & $(0.0130)$ & $(0.0124)$ & $(0.0127)$ & $(0.0127)$ \\
\hline & Pop $\left(000^{\prime} s\right)^{2}$ & $-0.0007^{* * *}$ & $-0.0007^{* * *}$ & $-0.0008^{* * *}$ & $-0.0007^{* * *}$ & $-0.0007^{* * *}$ & $-0.0008^{* * *}$ \\
\hline & & $(0.0002)$ & $(0.0002)$ & $(0.0002)$ & $(0.0002)$ & $(0.0002)$ & $(0.0002)$ \\
\hline \multirow{28}{*}{ 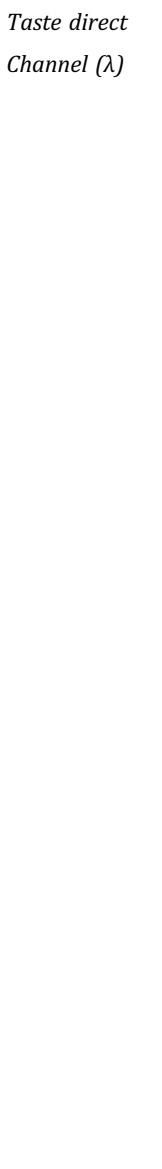 } & $\mathrm{HH}$ w/child (\%) & $0.0649^{* * *}$ & $0.0742^{* * *}$ & $0.0867^{* * *}$ & $0.0680^{* * *}$ & $0.0758^{* * *}$ & $0.0829 * * *$ \\
\hline & & $(0.0215)$ & $(0.0231)$ & $(0.0224)$ & $(0.0182)$ & $(0.0192)$ & $(0.0192)$ \\
\hline & $\mathrm{HH}$ w/child & $-0.0007^{* * *}$ & $-0.0008^{* * *}$ & $-0.0009^{* * *}$ & $-0.0007^{* * *}$ & $-0.0008^{* * *}$ & $-0.0009^{* * *}$ \\
\hline & $(\%)^{2}$ & $(0.0003)$ & $(0.0003)$ & $(0.0003)$ & $(0.0002)$ & $(0.0002)$ & $(0.0002)$ \\
\hline & Nonwhite (\%) & $-0.0265^{* * *}$ & $-0.0320^{* * *}$ & $-0.0313^{* * *}$ & $-0.0260^{* * *}$ & $-0.0313^{* * *}$ & $-0.0303^{* * *}$ \\
\hline & & $(0.0098)$ & $(0.0097)$ & $(0.0097)$ & $(0.0097)$ & $(0.0096)$ & $(0.0097)$ \\
\hline & Nonwhite $(\%)^{2}$ & $0.0004^{* * *}$ & $0.0004^{* * *}$ & $0.0005^{* * *}$ & $0.0004^{* * *}$ & $0.0004^{* * *}$ & $0.0004^{* * *}$ \\
\hline & & $(0.0001)$ & $(0.0001)$ & $(0.0001)$ & $(0.0001)$ & $(0.0001)$ & $(0.0001)$ \\
\hline & SNAP part (\%) & $0.0438^{* * *}$ & $0.0437^{* * *}$ & $0.0491^{* * *}$ & $0.0484^{* * *}$ & $0.0474^{* * *}$ & $0.0532^{* * *}$ \\
\hline & & $(0.0160)$ & $(0.0155)$ & $(0.0157)$ & $(0.0162)$ & $(0.0157)$ & $(0.0158)$ \\
\hline & SNAP part $(\%)^{2}$ & $-0.0008^{*}$ & $-0.0008^{* *}$ & $-0.0010^{* *}$ & $-0.0008^{*}$ & $-0.0008^{* *}$ & $-0.0010^{* *}$ \\
\hline & & $(0.0004)$ & $(0.0004)$ & $(0.0004)$ & $(0.0004)$ & $(0.0004)$ & $(0.0004)$ \\
\hline & HH size & -0.8221 & 0.3141 & 0.4088 & $-0.7156^{* * *}$ & $-0.5806^{* * *}$ & $-0.6042^{* * *}$ \\
\hline & & $(1.4724)$ & $(1.8956)$ & (1.7949) & (0.1916) & (0.1973) & $(0.1968)$ \\
\hline & $\mathrm{HH} \operatorname{size}^{2}$ & 0.0312 & -0.1718 & -0.1933 & & & \\
\hline & & (0.2943) & $(0.3794)$ & $(0.3601)$ & & & \\
\hline & Bach\&higher & $0.0257^{* * *}$ & $0.0247^{* *}$ & $0.0236^{* *}$ & $0.0218^{* * *}$ & $0.0198^{* * *}$ & $0.0217^{* * *}$ \\
\hline & $(\%)$ & $(0.0096)$ & $(0.0096)$ & $(0.0095)$ & $(0.0037)$ & $(0.0037)$ & $(0.0038)$ \\
\hline & Bach\&higher ${ }^{2}$ & 0.0000 & -0.0001 & 0.0000 & & & \\
\hline & $(\%)$ & $-(0.0001)$ & $(0.0001)$ & $(0.0001)$ & & & \\
\hline & Med age & 0.0154 & -0.0121 & -0.0400 & $-0.0207^{* *}$ & $-0.0148^{*}$ & $-0.0190^{* *}$ \\
\hline & & $-(0.0583)$ & $(0.0618)$ & $(0.0602)$ & $(0.0086)$ & $(0.0090)$ & $(0.0089)$ \\
\hline & Med age ${ }^{2}$ & -0.0004 & 0.0000 & 0.0003 & & & \\
\hline & & $(0.0007)$ & $(0.0007)$ & $(0.0007)$ & & & \\
\hline & Med inc & -0.0927 & -0.0902 & -0.0982 & -0.0137 & -0.0118 & -0.0182 \\
\hline & & $(0.0652)$ & $(0.0669)$ & $(0.0674)$ & $(0.0255)$ & $(0.0255)$ & $(0.0263)$ \\
\hline & Med inc ${ }^{2}$ & 0.0035 & 0.0039 & 0.0040 & & & \\
\hline & & $(0.0026)$ & $(0.0027)$ & $(0.0027)$ & & & \\
\hline \multirow{4}{*}{$\begin{array}{l}\text { Number of } \\
\text { Farms }(M)\end{array}$} & $\mathrm{F} \& \mathrm{~V}$ farms & $0.0214^{* * *}$ & $0.0235^{* * *}$ & $0.0207^{* * *}$ & $0.0213^{* * *}$ & $0.0234^{* * *}$ & $0.0204^{* * *}$ \\
\hline & & $(0.0058)$ & $(0.0057)$ & $(0.0058)$ & $-(0.0058)$ & $(0.0057)$ & $(0.0057)$ \\
\hline & No farms & $-0.2282^{*}$ & $-0.3111^{* *}$ & -0.2179 & $-0.2274^{*}$ & $-0.3153^{* *}$ & $-0.2243^{*}$ \\
\hline & & $(0.1323)$ & $(0.1368)$ & $(0.1344)$ & $-(0.1319)$ & $(0.1356)$ & $(0.1335)$ \\
\hline \multirow{4}{*}{$\begin{array}{l}\text { Establishment } \\
\text { Cost (E) }\end{array}$} & Hous. Dens & $-0.0629^{*}$ & & $-0.1658^{* * *}$ & $-0.0636^{*}$ & & $-0.1610^{* * *}$ \\
\hline & & $(0.0382)$ & & $(0.0554)$ & $(0.0370)$ & & $(0.0544)$ \\
\hline & Hous. Dens ${ }^{2}$ & $0.0015^{*}$ & & $0.0028^{* * *}$ & $0.0015^{* *}$ & & $0.0027^{* * *}$ \\
\hline & & $(0.0008)$ & & $(0.0010)$ & $(0.0008)$ & & $(0.0010)$ \\
\hline
\end{tabular}


Table 4. Continued

\begin{tabular}{|c|c|c|c|c|c|c|c|}
\hline & Variable & Model 1 & Model 2 & Model 3 & Model 4 & Model 5 & Model 6 \\
\hline & Small est & & $0.1769^{* *}$ & $0.3173^{* * *}$ & & $0.1810^{* * *}$ & $0.3103^{* * *}$ \\
\hline & /sq mile & & $-(0.0690)$ & $(0.0837)$ & & $(0.0647)$ & $(0.0806)$ \\
\hline & Small est & & $-0.0018^{* *}$ & $-0.0032^{* * *}$ & & $-0.0019^{* *}$ & $-0.0032^{* * *}$ \\
\hline & $/$ sq mile $^{2}$ & & $(0.0009)$ & $(0.0010)$ & & $(0.0008)$ & $(0.0009)$ \\
\hline & ML est & & -0.4404 & $-0.6274^{* *}$ & & $-0.4878^{*}$ & $-0.6576^{* *}$ \\
\hline & / sq mile & & $(0.2684)$ & $(0.2728)$ & & $(0.2501)$ & $(0.2622)$ \\
\hline & ML est & & 0.0106 & 0.0153 & & 0.0129 & 0.0171 \\
\hline & / sq mile ${ }^{2}$ & & $(0.0142)$ & $(0.0133)$ & & $(0.0131)$ & $(0.0125)$ \\
\hline Channel & $\begin{array}{l}\text { Fruit \& veg } \\
\quad \text { wholesalers }\end{array}$ & -0.0997 & $-0.1164^{*}$ & -0.0937 & -0.1026 & $-0.1186^{*}$ & -0.0959 \\
\hline Margins & Wholesalers & $(0.0659)$ & $(0.0674)$ & $(0.0655)$ & $(0.0660)$ & $(0.0676)$ & $(0.0660)$ \\
\hline \multirow[t]{6}{*}{$\left(\theta_{a} \theta_{b}\right)$} & $\begin{array}{l}\text { Fruit \& veg } \\
\quad \text { wholesalers }\end{array}$ & $0.0030^{*}$ & $0.0033^{* *}$ & $0.0029^{*}$ & $0.0030^{*}$ & $0.0033^{* *}$ & $0.0029^{*}$ \\
\hline & Wholesalers ${ }^{2}$ & $(0.0016)$ & $(0.0016)$ & $(0.0016)$ & $(0.0016)$ & $(0.0016)$ & $(0.0016)$ \\
\hline & Grocery stores & $0.1809^{* * *}$ & $0.1726^{* * *}$ & $0.1712^{* * *}$ & $0.1851^{* * *}$ & $0.1751^{* * *}$ & $0.1726^{* * *}$ \\
\hline & & $(0.0402)$ & $(0.0409)$ & $(0.0409)$ & $(0.0402)$ & $(0.0409)$ & $(0.0409)$ \\
\hline & Grocery stores $^{2}$ & $-0.0055^{* *}$ & $-0.0052^{* *}$ & $-0.0052^{* *}$ & $-0.0057^{* *}$ & $-0.0053^{* *}$ & $-0.0052^{* *}$ \\
\hline & & $(0.0026)$ & $(0.0026)$ & $(0.0026)$ & $(0.0026)$ & $(0.0026)$ & $(0.0026)$ \\
\hline Pseudo R2 & & 0.204 & 0.205 & 0.21 & 0.203 & 0.205 & 0.209 \\
\hline AIC & & 1919.5 & 1919.949 & 1913.98 & 1912.965 & 1913.411 & 1907.732 \\
\hline BIC & & 2089.568 & 2100.988 & 2105.992 & 2061.088 & 2072.507 & 2077.799 \\
\hline
\end{tabular}

Note: $*, * *$, and ${ }^{* * *}$ represent 10,5 and 1 percent significance levels, respectively. Robust standard errors in parenthesis. State-level fixed effects and constants omitted for brevity.

this outlet, this effect may be limited to small patronage numbers, given the concave nature of the estimated relationship. As SNAP-recipient spending at farm-direct outlets is small, compared both in terms of total SNAP purchases (according to USDA FNS, in 2014 this amounted to circa 0.02 percent of total redemption $^{13}$ ) and as a fraction of direct sales (less than 1 percent of total direct sales), other factors may limit the viability of SNAP participants as suitable FM clientele, which are likely not to be captured by our ceteris paribus estimates. ${ }^{14}$ Finally, consistent with existing studies we also find that income is not significantly associated with FM participation or with the probability of observing more FMs (e.g., Wolf, Spittler, and Ahern 2005, Zepeda 2009).

13 The USDA FNS reports a SNAP redeemed amounts of $\$ 13,470,334$ at FMs in FY 2014, over a total of circa $\$ 70$ billion SNAP benefits redeemed. For additional information, see the SNAP Retailer Management 2014 Annual Report at http://www.fns.usda.gov/sites/default/files/snap/ 2014-SNAP-Retailer-Management-Annual-Report.pdf.

14 We thank an anonymous reviewer for a series of comments that helped contextualize this result. 
The coefficients associated with the variables capturing the potential pool of farmers participating in an FM $(M)$ are consistent with our expectations. As the number of fruit and vegetables farm operations increases, so do FMs' probability across all model specifications. Further, the absence of farming activities in a zip code is negatively associated with the probability of finding one or more farmers markets. ${ }^{15}$ With regards to establishment costs $(E)$, we find that as housing density and the number of medium/large establishments increases, the probability of observing one or more FMs declines. As the quadratic terms of these variables produce positive and statistically significant coefficients, our empirical findings are consistent with the theoretical model. Also, per our expectation small establishments are inversely related to the presence of FMs.

Estimates for the set of variables related to channel margins $(\theta a, \theta b)$ provide a less clear picture. The number of fruit and vegetable wholesalers is only weakly associated with the probability of observing a positive number of FMs. The estimated coefficients for the number of grocery stores indicates a positive and decreasing relationship with participation, suggesting that grocery stores and FMs may be complementary shopping experiences (consistent with Morgan and Alipoe 2001, and Singleton, Sen, and Affuso 2015). This could be indicative of demand for similar services or co-location strategies where both types of outlets try to locate in areas with larger demand.

\section{Additional Estimates and Robustness Checks}

Our OP estimates are valid if the proportional odds (aka parallel regression) assumption is satisfied. That is, the parameter estimates are assumed to be the same for all levels of the dependent variable. We estimated a constrained generalized ordered probit (CGOP) to verify whether the proportional odds assumption is violated in our estimates. To that end, we used a stepwise procedure, starting from a fully unconstrained model, and then successively constraining each parameter, until a Wald test indicated that the constrained parameters did not violate the parallel regression assumption (see Williams 2006 for a more extensive discussion).

We apply this procedure to model specifications 4 and $6 .{ }^{16}$ The majority of the estimated parameters satisfy the proportional odds assumptions (24 out of 30 parameters for specification 4; 29 out of 34 parameters for specification 6), providing estimates consistent with those presented in Table 4 . While some parameters violate the proportional odds assumption, variables for which the

\footnotetext{
15 Even though we only included measures of $M$ within the same zip code, farmers selling at FMs travel average distances varying from 23.2 to 46.8 miles to reach an FM's site (Lohr et al. 2011). As we could not establish the correct area of influence for a particular FM, we did not account for farmers in neighboring zip codes. We elaborate on the likely effect of this choice on our results and how future analyses could overcome this limitation in the conclusion section.

16 The results of these models are omitted for brevity, and available upon request.
} 
proportional odds assumption is violated show parameters with either different sign or significance levels across model specifications. As Williams (2006) warns that a violation of the parallel lines assumption can be based on empirical "chance," given the lack of consistency of these estimates, we consider our OP estimates the preferred specification.

As there is evidence that, at least in the case of retail outlets, population in neighboring areas can also affect location decision (Mushinski and Weiler 2002; Thilmany et al. 2005), spatial interdependencies may also affect FMs' location. If not accounted for, such spatial effects may lead to biased results. Thus, we re-estimated model specifications 4 and 6 , using a spatial autoregressive ordered probit that accounted for the existence of spatial correlation of the unobserved drivers of FM location in a given zip code. The estimation algorithm used was adapted from the Bayesian procedure proposed by Wang and Kockelman (2009) for estimating a spatial dynamic ordered probit. ${ }^{17}$

The Bayesian estimates of the ordered probit (OP) and spatial ordered probit (SOP) are presented in Table 5. Three main findings can be highlighted. First, despite the magnitude of the estimated spatial ordered probit coefficients differing from those obtained using maximum likelihood, their sign and significance levels are generally consistent with those reported in Table 4, supporting the robustness of our results. One notable difference is that the income's parameter (still negative) is now statistically significant. Second, a comparison of OP and SOP results shows that in most cases, once spatial correlation of the error terms is taken into account, both the magnitude and the significance level of the coefficients decreases. This indicates that given our data, spatial patterns in unobserved zip code features are likely to be relevant both in determining farmers' participation in FMs and on the location of FMs. Third, even though in both model specifications the estimated spatial autocorrelation coefficient is statistically significant, our estimates are not conclusive regarding which estimator provides the best fit for the data. Based on the Deviance Inflation Criterion (DIC), we find that the SOP is favored to the OP in model 4. Alternatively, for model 6, we find the opposite. Thus, even though we find evidence that the residuals may be spatially correlated, we have no conclusive reason to believe that the spatial estimator produces more reliable estimates that those presented in Table 4.

\section{Marginal Effects and Discussion}

Our discussion so far has been limited to the sign and significance of the estimated coefficient and whether or not they were consistent with the

\footnotetext{
17 Our estimation is similar to that described in LeSage (2000). We thankfully acknowledge Xiaokun (Cara) Wang at the Rensselaer Polytechnic Institute for graciously providing us with the Matlab code for estimating the Bayesian spatial dynamic ordered probit.
} 
Table 5. Estimation Results of Bayesian Ordered Probit and Spatial Ordered Probit (1000 burn in - 1000 posterior iteration) Model with Dependent Variable FM(12)

\begin{tabular}{|c|c|c|c|c|c|}
\hline & \multirow[b]{2}{*}{ Variable } & \multicolumn{2}{|l|}{ Model 4} & \multicolumn{2}{|l|}{ Model 6} \\
\hline & & OP & SOP & OP & SOP \\
\hline Market & Pop (000s) & $0.3881^{* * *}$ & $0.2431^{* *}$ & $0.4084^{* * *}$ & $0.3152^{* *}$ \\
\hline \multirow[t]{3}{*}{ Size $(S)$} & & $(0.1169)$ & $(0.0494)$ & $(0.1185)$ & $(0.0827)$ \\
\hline & Pop $\left(000^{\prime} s\right)^{2}$ & $-0.0056^{* * *}$ & $-0.0036^{* *}$ & $-0.0060^{* * *}$ & $-0.0047^{* *}$ \\
\hline & & $(0.0017)$ & $(0.0008)$ & (0.0019) & $(0.0014)$ \\
\hline Taste direct & $\begin{array}{l}\mathrm{HH} \text { w/child } \\
\text { (\%) }\end{array}$ & $0.1172^{* *}$ & 0.1381 & $0.144^{* *}$ & 0.1194 \\
\hline \multirow[t]{19}{*}{ Channel $(\lambda)$} & & $(0.1020)$ & $(0.0586)$ & $(0.0843)$ & $(0.0677)$ \\
\hline & $\begin{array}{c}\mathrm{HH} \mathrm{w/child} \\
(\%)^{2}\end{array}$ & $-0.0013^{*}$ & -0.002 & $-0.0018^{* *}$ & -0.0011 \\
\hline & & $(0.0013)$ & $(0.0007)$ & $(0.0010)$ & $(0.0009)$ \\
\hline & Nonwhite (\%) & $-0.2199^{* * *}$ & $-0.1025^{*}$ & $-0.2233^{* * *}$ & $-0.1792^{*}$ \\
\hline & & $(0.0597)$ & $(0.0632)$ & $(0.0995)$ & $(0.0654)$ \\
\hline & $\begin{array}{l}\text { Nonwhite } \\
(\%)^{2}\end{array}$ & $0.0029 * * *$ & 0.0012 & $0.0028^{* * *}$ & $0.0024^{* *}$ \\
\hline & & (0.0009) & $(0.0007)$ & $(0.0012)$ & $(0.0010)$ \\
\hline & $\begin{array}{l}\text { SNAP part } \\
(\%)\end{array}$ & $0.2556^{* *}$ & $0.2078^{*}$ & $0.2155^{* * *}$ & $0.2088^{* *}$ \\
\hline & & $(0.1210)$ & $(0.1229)$ & $(0.0849)$ & $(0.0734)$ \\
\hline & $\begin{array}{l}\text { SNAP part } \\
(\%)^{2}\end{array}$ & $-0.0056^{* *}$ & -0.0032 & $-0.0036^{*}$ & $-0.0039^{*}$ \\
\hline & & $(0.0022)$ & $(0.0029)$ & $(0.0023)$ & $(0.0022)$ \\
\hline & $\begin{array}{l}\text { Bach \& higher } \\
\quad(\%)\end{array}$ & $-2.819^{* * *}$ & -1.7829 & $-2.1864^{* * *}$ & $-2.2296^{* * *}$ \\
\hline & & (1.1213) & $(0.7577)$ & $(0.6600)$ & $(0.6940)$ \\
\hline & HH size & $0.1964^{* * *}$ & $0.1132^{* * *}$ & $0.1543^{* * *}$ & $0.1059^{* * *}$ \\
\hline & & $(0.0378)$ & $(0.0234)$ & $(0.0300)$ & $(0.0233)$ \\
\hline & Med age & $-0.0614^{* *}$ & -0.0195 & $-0.0317^{* *}$ & -0.0217 \\
\hline & & $(0.0155)$ & $(0.0251)$ & $(0.0189)$ & $(0.0131)$ \\
\hline & Med Income & $-0.2847^{* * *}$ & $-0.1977^{* *}$ & $-0.1979 * * *$ & $-0.1605^{* *}$ \\
\hline & & $(0.0742)$ & $(0.0443)$ & $(0.0610)$ & $(0.0224)$ \\
\hline Number of & $\mathrm{F} \& \mathrm{~V}$ farms & $0.1256^{* * *}$ & $0.1399^{* * *}$ & $0.1248^{* * *}$ & $0.1195^{* *}$ \\
\hline Farms $(M)$ & & $(0.0368)$ & $(0.0368)$ & $(0.0472)$ & $(0.0312)$ \\
\hline
\end{tabular}


Table 5. Continued

\begin{tabular}{|c|c|c|c|c|c|}
\hline & \multirow[b]{2}{*}{ Variable } & \multicolumn{2}{|l|}{ Model 4} & \multicolumn{2}{|l|}{ Model 6} \\
\hline & & OP & SOP & OP & SOP \\
\hline & No farms & $-1.2398^{*}$ & $-1.3936^{*}$ & -0.716 & $-0.977^{*}$ \\
\hline & & $(0.7488)$ & $(0.7289)$ & $(0.6177)$ & $(0.8074)$ \\
\hline \multirow{12}{*}{$\begin{array}{l}\text { Establishment } \\
\text { Cost }(E)\end{array}$} & Hous. Dens & $-0.7295^{* * *}$ & $-0.6733^{* *}$ & $-1.125^{* *}$ & $-0.7723^{* *}$ \\
\hline & & $(0.2967)$ & $(0.2080)$ & $(0.3444)$ & $(0.5341)$ \\
\hline & Hous. Dens ${ }^{2}$ & $0.0157^{* *}$ & $0.0176^{* *}$ & $0.0202^{* *}$ & $0.0114^{*}$ \\
\hline & & $(0.0071)$ & $(0.0067)$ & $(0.0069)$ & $(0.0103)$ \\
\hline & Small est & & & 0.1998 & 0.0519 \\
\hline & /sq mile & & & $(0.8546)$ & $(0.8423)$ \\
\hline & Small est & & & -0.0135 & -0.0250 \\
\hline & $/$ sq mile $^{2}$ & & & $(0.0344)$ & $(0.0267)$ \\
\hline & ML est & & & 0.7059 & 0.8147 \\
\hline & /sq mile & & & $(0.6795)$ & $(0.6607)$ \\
\hline & ML est & & & 0.0067 & 0.0256 \\
\hline & /sq mile ${ }^{2}$ & & & $(0.0236)$ & $(0.0161)$ \\
\hline $\begin{array}{l}\text { Channel } \\
\text { wholesalers }\end{array}$ & $\begin{array}{l}\text { Fruit \& veg } \\
-0.8861^{*}\end{array}$ & -0.592 & -0.4508 & $-0.6881^{*}$ & \\
\hline Margins & Wholesalers & $(0.4709)$ & $(0.4970)$ & $(0.3453)$ & $(0.3461)$ \\
\hline \multirow[t]{6}{*}{$\begin{array}{l}\left(\theta_{a}, \theta_{b}\right) \\
\quad \text { wholesalers }\end{array}$} & $\begin{array}{l}\text { Fruit \& veg } \\
0.0259^{* *}\end{array}$ & 0.0194 & $0.0174^{*}$ & $0.0209^{* *}$ & \\
\hline & Wholesalers $^{2}$ & $(0.0136)$ & $(0.0122)$ & $(0.0092)$ & $(0.0103)$ \\
\hline & $\begin{array}{l}\text { Grocery } \\
\text { stores }\end{array}$ & $1.4944^{* * *}$ & $1.3365^{* * *}$ & $1.2004^{* * *}$ & $0.9767^{* *}$ \\
\hline & & $(0.3756)$ & $(0.3592)$ & $(0.3931)$ & $(0.1854)$ \\
\hline & $\begin{array}{l}\text { Grocery } \\
\text { stores }^{2}\end{array}$ & $-0.0456^{* * *}$ & $-0.0433^{* * *}$ & $-0.041^{* * *}$ & -0.0294 \\
\hline & & $(0.0142)$ & $(0.0156)$ & $(0.0208)$ & $(0.0120)$ \\
\hline $\begin{array}{l}\text { Residual } \\
\text { Correlation } \\
\text { Coefficient }\end{array}$ & & $0.9975^{* * *}$ & & $0.9971^{* *}$ & \\
\hline Variance & & $71.9334^{* * *}$ & $67.5198^{* * *}$ & $53.2897^{* * *}$ & $40.7684^{*}$ \\
\hline DIC & & 880.017 & 869.513 & 995.992 & 1178.41 \\
\hline
\end{tabular}

Note: $*, * *$, and ${ }^{* * *}$ represent 10,5 and 1 percent significance levels, respectively. Pseudo standard errors in parenthesis. State-level fixed effects and constants omitted for brevity. 
expectations of our theoretical model. Next, we used the estimates from model 4 (the best-performing model specification) to assess how changes in the independent variables affect the probability of observing a positive number of FMs $(F M \geq 1)$, one FM, $(F M=1)$ or two or more FMs $(F M \geq 2)$, calculated at the sample average. These average marginal effects are reported in Table 6 (ML estimates only).

A unitary increase in the zip code population $(1,000$ people) is associated with higher probability of observing one or more FMs by 0.86 percent; one FM by 0.62 percent; and 2 or more FMs by 0.23 percent. Going forward, we report all the results in the same order: one or more FMs; one FM, and 2 or more FMs. An additional 1 percent of households with children, is associated with a higher probability of having a positive number of FMs of 0.26 percent, 0.19 percent, and 0.07 percent. For every percentage of the population being nonwhite, the probability of observing one or more FMs declines (on average) by roughly 10.5 percent, 7.5 percent, and 2.8 percent. On average, a 1 percent increase in the share of population in SNAP is associated with an increase of 0.81 percent, 0.59 percent, and 0.22 percent.

Zip codes inhabited by smaller households are characterized by a higher probability of having one or more FMs. A unitary increase in the average household size is associated with a decline in FMs of 17 percent, 12.34 percent, and 4.63 percent. A one percent increase in the share of population with a bachelor degree or higher, is associated with a higher probability of having FMs by 0.52 percent, 0.38 percent, and 0.14 percent. Last, an increase in average age by one year, is related to lower probabilities of observing one or more FMs by 0.5 percent, 0.36 percent, and 0.13 percent. Consistent with the sign and significance of the estimated coefficients, income has no association with the probability of observing more FMs.

With respect to the variables capturing the potential pool of participant farmers $(M)$, an additional fruit and vegetable farm in a zip code is associated with a higher probability of observing FMs by 0.51 percent, 0.37 percent, and 0.14 percent. The absence of farming activities in the same zip code where the farm is located is associated with lower the probability of FMs by 5.4 percent, 3.92 percent, and 1.47 percent. A unitary increase in the proxy for the opportunity cost of establishment (housing density) is associated with a decline of the probability of observing one or more FMs of 1.47 percent, 1.07 percent, and 0.4 percent. Additional fruit and vegetable wholesalers do not have a statistically significant effect. Zip codes with a higher number of grocery stores, show a higher probability of having FMs by roughly 3.93 percent, 2.86 percent, and 1.07 percent.

These marginal effects help describe areas that are more conducive to supporting the establishment of one or more FMs (in New England). In summary, the positive estimated effects of population show that larger markets are more likely to support one or more FMs, which is not surprising. In addition, the profile of areas supporting one or more FMs is comprised of younger, more highly educated individuals residing in areas with smaller 
Table 6. Average Marginal Effects on the Probability of Observing 1 or More FM (Pr(NFM $\geq 1)$ ); one FM $(\operatorname{Pr}(\mathrm{NFM}=1))$ and Two or More FMs (Pr $(\mathrm{NFM} \geq 2)$ ); Model 4 (ML only)

\begin{tabular}{|c|c|c|c|c|}
\hline & Variable & $\begin{array}{l}\text { Pr } \\
(N F M \geq 1)\end{array}$ & $\begin{array}{l}\text { Pr } \\
(\mathrm{NFM}=1)\end{array}$ & $\begin{array}{l}\operatorname{Pr} \\
(N F M \geq 2)\end{array}$ \\
\hline Market & Pop $\left(000^{\prime} s\right)$ & $0.0086^{* * *}$ & $0.0062^{* * *}$ & $0.0023^{* * *}$ \\
\hline Size $(S)$ & & $(0.0022)$ & $(0.0016)$ & $(0.0006)$ \\
\hline Taste direct & $\mathrm{HH}$ w/child (\%) & $0.0026^{* *}$ & $0.0019 * *$ & $0.0007^{* *}$ \\
\hline \multirow[t]{13}{*}{ Channel $(\lambda)$} & & $(0.0012)$ & $(0.0009)$ & $(0.0003)$ \\
\hline & Nonwhite (\%) & $-0.1035^{* * *}$ & $-0.0752^{* * *}$ & $-0.0282^{* * *}$ \\
\hline & & $(0.0386)$ & $(0.0281)$ & $(0.0105)$ \\
\hline & SNAP part (\%) & $0.0081^{* * *}$ & $0.0059^{* * *}$ & $0.0022^{* * *}$ \\
\hline & & $(0.0024)$ & $(0.0017)$ & $(0.0007)$ \\
\hline & Bach \& higher (\%) & $0.0052^{* * *}$ & $0.0038^{* * *}$ & $0.0014^{* * *}$ \\
\hline & & $(0.0009)$ & $(0.0006)$ & $(0.0002)$ \\
\hline & HH Size & $-0.1698^{* * *}$ & $-0.1234^{* * *}$ & $-0.0463^{* * *}$ \\
\hline & & $(0.0455)$ & $(0.0331)$ & $(0.0124)$ \\
\hline & Med age & $-0.0049^{* *}$ & $-0.0036^{* *}$ & $-0.0013^{* *}$ \\
\hline & & $(0.0020)$ & $(0.0015)$ & $(0.0006)$ \\
\hline & Med Income & -0.0033 & -0.0024 & -0.0009 \\
\hline & & $(0.0060)$ & $(0.0044)$ & $(0.0017)$ \\
\hline \multirow{4}{*}{$\begin{array}{l}\text { Number of } \\
\text { Farms }(M)\end{array}$} & $\mathrm{F} \& \mathrm{~V}$ farms & $0.0051^{* * *}$ & $0.0037^{* * *}$ & $0.0014^{* * *}$ \\
\hline & & $(0.0014)$ & $(0.0010)$ & $(0.0004)$ \\
\hline & No farms & $-0.0540^{*}$ & $-0.0392^{*}$ & $-0.0147^{*}$ \\
\hline & & $(0.0313)$ & $(0.0228)$ & $(0.0085)$ \\
\hline Establishment & Hous. Dens & $-0.0147^{*}$ & $-0.0107^{*}$ & $-0.0040^{*}$ \\
\hline Cost (E) & & $(0.0086)$ & $(0.0062)$ & $(0.0023)$ \\
\hline \multirow{4}{*}{$\begin{array}{l}\text { Channel } \\
\text { Margins }\left(\theta_{a}, \theta_{b}\right)\end{array}$} & Fruit \& veg wholesalers & -0.0242 & -0.0176 & -0.0066 \\
\hline & & $(0.0156)$ & $(0.0113)$ & $(0.0042)$ \\
\hline & Grocery stores & $0.0393^{* * *}$ & $0.0286^{* * *}$ & $0.0107^{* * *}$ \\
\hline & & $(0.0079)$ & $(0.0057)$ & $(0.0021)$ \\
\hline
\end{tabular}

Note: ${ }^{*}, * *$, and ${ }^{* * *}$ represent 10,5 , and 1 percent significance levels, respectively. Standard errors in parenthesis are approximated. The average marginal effects of a variable $X$, introduced in the model as quadratic, whose parameters are, $\beta_{X}$ and $\beta_{X^{2}}$, for the linear and quadratic terms, respectively, are calculated as $\frac{\partial \operatorname{Pr}\left(N^{*} \geq 1\right)}{\partial X}=\Phi\left(\mu_{1}-\overline{\mathbf{X}}^{\prime} \boldsymbol{\beta}\right)\left(\beta_{X}+2 \beta_{X^{2}} \bar{X}\right) ; \quad \frac{\partial \operatorname{Pr}\left(N^{*}=1\right)}{\partial X}=$ $\left[\Phi\left(\mu_{2}-\overline{\mathbf{X}}^{\prime} \boldsymbol{\beta}\right)-\Phi\left(\mu_{1}-\overline{\mathbf{X}}^{\prime} \boldsymbol{\beta}\right)\right]\left(\beta_{X}+2 \beta_{X^{2}} \bar{X}\right) ; \frac{\partial \operatorname{Pr}\left(N^{*} \geq 2\right)}{\partial X}=\Phi\left(\mu_{2}-\overline{\mathbf{X}}^{\prime} \boldsymbol{\beta}\right)\left(\beta_{X}+2 \beta_{X^{2}} \bar{X}\right), \bar{X}$ where is the average of the variable of interest, $\overline{\mathbf{X}}^{\prime} \boldsymbol{\beta}$ is the linear prediction obtained multiplying the parameters' values times the average of the explanatory variables, and the $\mu_{s}$ are the estimated ordered probit constants. 
households but with a higher share of households with children. This provides greater detail about the characteristics of consumers who are likely to support FMs. Other factors supporting the location of FMs appear to be the existence of a pool of farmers to draw from, and complementary services such as grocery stores. Detrimental effects include the absence of farms and limitations in finding adequate space for establishing the market itself (i.e., housing density effects).

Given that some of the variables used in the analysis enter the model as quadratic terms, the marginal effect for each of these variables will be a nonlinear function of the variable itself. This leads to additional nuances in our results. To illustrate these nuances, we depicted in Figure 3 how the marginal effects of total population, the number of grocery stores and fruit and vegetable wholesalers change with the values of each independent variable. The marginal effects of population on the probability of observing a positive number of FMs (top panel of Figure 3) is higher at low population levels (about 1.42 percent for zip codes with 1,000 people), and it reaches zero at the $96^{\text {th }}$ percentile of the population distribution (that is, at roughly 33,340 people). This indicates that while a larger market may help the establishment of one or more FMs if the initial population is small, more population does not contribute to having a larger number of FMs in areas where the market potential is already large. As shown in the middle panel of Figure 3, the positive spillover and co-location effects of grocery stores is associated with a 4.35 percent increase in the probability of observing one or more FMs when one adds an additional grocery store in a zip code with one pre-existing store. This relationship becomes null in areas with more than 16 stores, which is 3 percent of our sample. This suggests that co-location helps the most in areas far from market saturation. Similarly, competition from one additional establishment belonging to a traditional distribution channel (e.g., fruits and vegetable wholesalers) is associated with a lower probability of observing FMs for values as large as 2.57 percent (bottom panel of Figure 3). In areas where there is a large number of wholesalers, their relationship with the probability of observing FMs becomes null.

\section{Conclusions}

Farmers markets give farmers the opportunity to acquire a larger share of the channel's margins, while improving access to fresh food for consumers. Not surprisingly, the number of farmers markets in the United States in the last two decades has tripled. However, a slowing growth rate suggests an approaching market saturation. As local planners and policy makers consider further expansion of farmers markets, a better understanding of the factors facilitating their establishment may help foster their development. In this analysis we present a theoretical model of farmers' participation in the marketing channel, and assess the economic forces determining FMs' existence using a simple empirical framework applied to zip-code-level data 

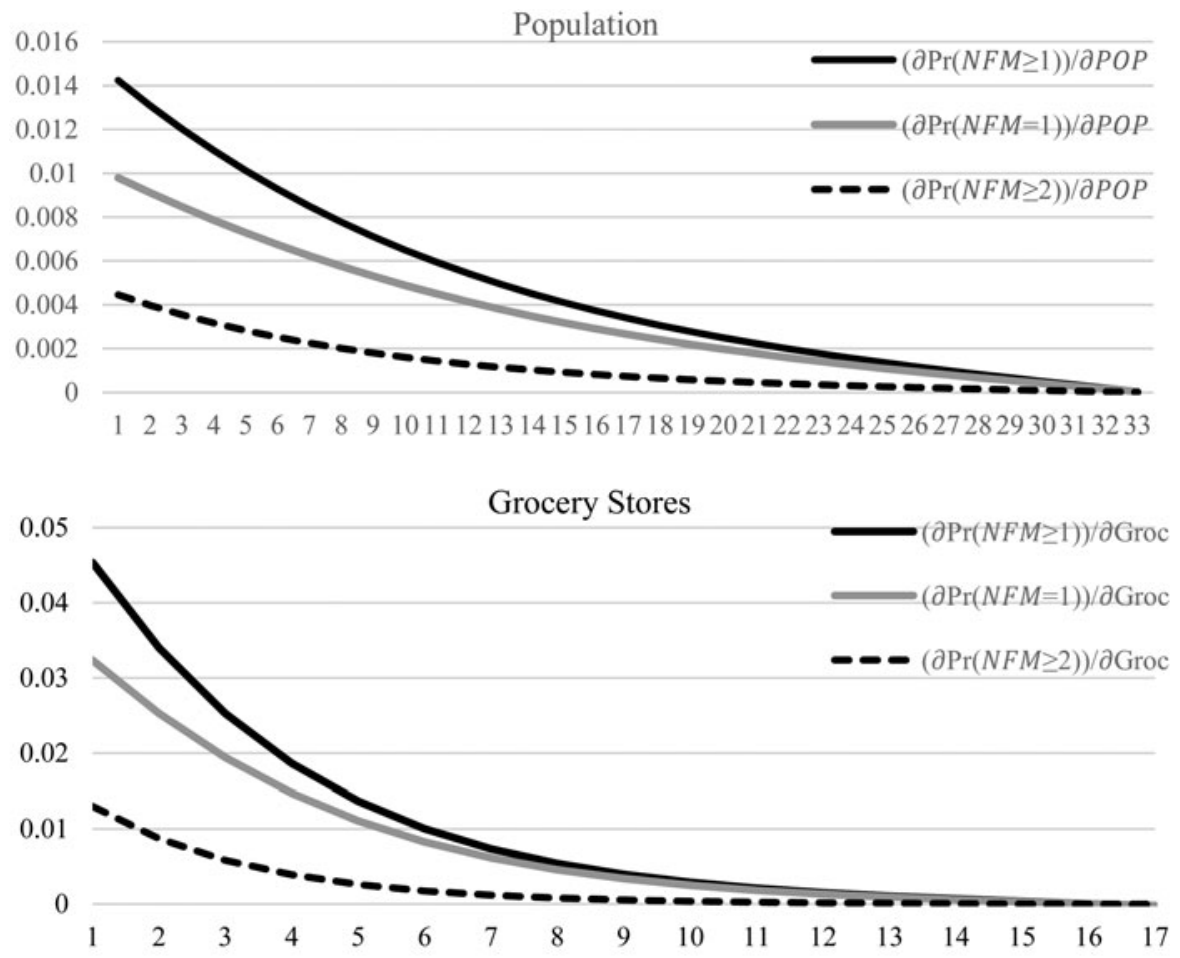

F\&V wholesalers

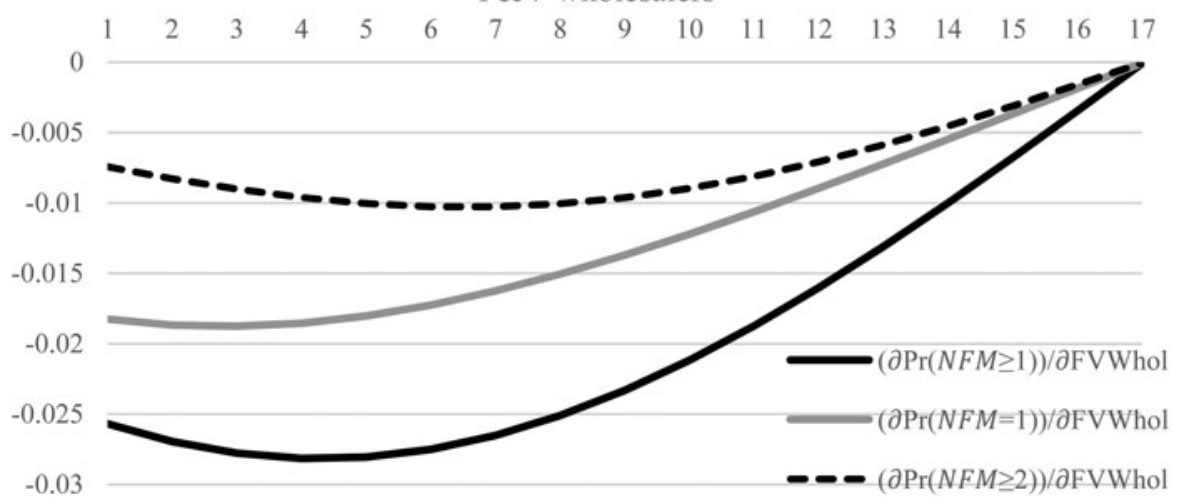

Figure 3. Marginal Effects of Selected Variables on the Probability of Observing 1 or More FMs $(\mathrm{NFM} \geq 1)$, 1 FM $(\mathrm{NFM}=1)$, or 2 or More FMs $(\mathrm{NFM} \geq 2)$

Source: Authors Calculations Based on Estimated Coefficients for Model Specification 4 (Model 4 (ML only); Y Axis: Marginal Effects; X Axis: Independent Variables' Values 
in New England. The results of our empirical analysis indicate that both demand and supply-side characteristics are significantly related to the establishment of FMs in a zip code.

Our results support previous research (e.g., Wolf, Spittler, and Ahern 2005, Zepeda 2009) identifying specific "target markets" for FMs in New England. In particular, the target demographic is identified as highly educated and younger individuals from smaller households but with a higher likelihood of having children, and lower likelihood of being ethnically diverse. At the same time, our theoretical model and empirical results highlight other relevant factors that affect the potential for FMs. Specifically, the role of market size and the extent of competition suggest a more nuanced understanding of the potential growth of FMs. Even though the existence of a larger pool of farmers from which to draw is positively associated with a higher probability of having a positive number of FMs, benefits from co-location with other types of outlets (that is, grocery stores) and competition from traditional channels (i.e., fruits and vegetable wholesalers) have nonlinear effects as well.

Our analysis is characterized by a number of limitations and could be expanded in several directions going forward. First, as pointed out by an anonymous reviewer, while it may make sense that consumers patronize FMs located in the same zip codes where they reside, it is less likely that farmers only sell at FMs located in the same zip code where their farm is located. As a result, our empirical choice of using only farmers located in the same zip code as the potential pool of farmers available for the formation of an FM, although convenient from an empirical standpoint, could introduce bias in our estimates. As the existing literature has already highlighted that farmers appear willing to travel farther distances to participate in FMs located in more populous areas (Lohr et al. 2011), the determination of the appropriate distance radius to consider to aggregate farms is challenging. Future research could expand the present analysis by assessing how farmers decide how far to travel to reach an FM, and how distance traveled affects FM formation.

Second, as we only examine a cross-sectional database, we are not able to capture the exit of FMs from a given zip code. Thus, we are not able to assess what market conditions contribute to the failure of FMs in a particular zip code, which could be addressed if a panel database of FM locations were available. As there are important FM quality differences, the role of individual FMs' characteristics (number of days open, weeks of operation, winter opening, number of stands, etc.) should be appropriately modeled in the future to assess what characteristics of a market are more appealing to consumers, and therefore increase their probability of survival.

Third, a result that warrants additional exploration is the positive association between the share of SNAP recipients' population and FM numbers. Even though this result appears in line with the goals of policies aimed to increase FM patronage by SNAP recipients, additional considerations should be taken into account. In particular, certain types of FMs may be more conducive to successfully marketing to SNAP recipients. 
Finally, our empirical analysis assesses the effect of specific market characteristics on the probability of observing one or more FMs. Although informative, our estimates do not speak to the potential of a specific market to actually host one or more FMs. An extension of this work could focus on the estimation of population thresholds (that is, the minimum number of people) needed to support one or more FMs (see Mushinski and Weiler, 2002, Thilmany et al., 2005, Bonanno et al., 2016). This would help shed light on how different policy levers could be implemented to facilitate the profitability of FMs in a given area.

\section{References}

Berning, J.P. 2012. "Access to Local Agriculture and Weight Outcomes." Agricultural and Resource Economics Review 41(1): 1-15.

Berry, S.T. 1992. "Estimation of a Model of Entry in the Airline Industry." Econometrica 60(4): 889-917.

Bresnahan, T.F. and P.C. Reiss. 1991. "Entry and Competition in Concentrated Markets." Journal of Political Economy 99(5): 977-1009.

Bimbo, F., A. Bonanno, G. Nardone and R. Viscecchia. 2015. "The Hidden Benefits of Short Supply Chains: Farmers Market, Supermarket Access and Adult Obesity in Italy." International Food and Agribusiness Management Review 18(1): 1-16.

Bonanno, A. 2012. "Food Deserts: Demand, Supply, and Economic Theory." Choices Magazine 3rd Quarter. 2012.

Bonanno, A., R. Cleary, L. Chenarides-Hall and S. J. Goetz. 2016. "Economic Drivers of Large Food Stores Access in the U.S." Invited paper presented at the 2016 Agricultural and Applied Economcis Association Boston, MA.

Brown, A. 2002. Farmers' Market Research 1940-2000: An Inventory and Review. American Journal of Alternative Agriculture 17(4): 167-176.

Brown, C. and S. Miller. 2008. "The Impacts of Local Markets: A Review of Research on Farmers Markets and Community Supported Agriculture (CSA)." American Journal of Agricultural Economics 90(5): 1298-1302.

Cone, C.A. and A. Myhre. 2000. "Community-Supported Agriculture: A Sustainable Alternative to Industrial Agriculture?" Human Organization 59(2): 187-197.

Frieden, T.R, W. Dietz and J. Collins. 2010. "Reducing Childhood Obesity through Policy Change: Acting Now to Prevent Obesity". Health Affairs 9: 357-363.

Gale, F., 1997. "Direct Farm Marketing as a Rural Development Tool." Rural Development Perspectives 12(2): 19-25.

Gilg, A.W. and M. Battershill. 1998. "Quality Farm Food in Europe: A Possible Alternative to the Industrialised Food Market and to Current Agri-environmental Policies: Lessons from France." Food Policy 23(1): 25-40.

Govindasamy, R., J. Italia, M. Zurbriggen, and F. Hossain. 2002. "Predicting Consumer Willingness-to-Purchase Value-Added Products at Direct Agricultural Markets." Journal of Food Products Marketing 8(1): 1-15.

Gumirakiza, J.D., K.R. Curtis and R. Bosworth. 2014. "Who Attends Farmers' Markets and Why? Understanding Consumers and Their Motivations." International Food and Agribusiness Management Review 17(2): 65-82.

Hunt, A. 2007. "Consumer Interactions and Influences on Farmers' Market Vendors." Agriculture and Food Systems 22: 54-66.

Johnson, R., R. Alison and T. Cowan. 2013. "The Role of Local Food Systems in U.S. Farm Policy CRS Report for Congress." Congressional Research Service. R42155. Available at http:// fas.org/sgp/crs/misc/R42155.pdf (accessed January 2015). 
La Trobe, H. 2001. “Farmers' Markets: Consuming Local Rural Produce." International Journal of Consumer Studies 25(3): 181-192.

LeSage, J.P. 2000. “Bayesian Estimation of Limited Dependent Variable Spatial Autoregressive Models." Geographical Analysis 32(1): 19-35.

Lohr, L., A. Diamond, C. Dicken, and M. David. 2011. "Mapping Competition Zones for Vendors and Customers in U.S. Farmers Markets." U.S. Dept. of Agriculture, Agricultural Marketing Service. September 2011.

Martinez, S., M. Hand, M. Da Pra, S. Pollack, K. Ralston, T. Smith, S. Vogel, S. Clark, L. Lohr, S. Low and C. Newman. 2010. Local Food Systems: Concepts, Impacts, and Issues, ERR 97, U.S. Department of Agriculture, Economic Research Service, May 2010.

Mazzeo, M.J. 2002. "Product Choice and Oligopoly Market Structure." RAND Journal of Economics 33(2): 221-242.

Morgan, T.K. and D. Alipoe. 2001. "Factors Affecting the Number and Type of Small-Farm Direct Marketing Outlets in Mississippi" Journal of Food Distribution Research 32(1): 125-132.

Mushinski, D. and S. Weiler. 2002. "A Note on the Geographic Interdependencies of Retail Market Areas." Journal of Regional Science 42(1): 75-86.

Pascucci, S., C. Cicatiello, S. Franco, B. Pancino and D. Marino. 2011. "Back to the Future? Understanding Change in Food Habits of Farmers' Market Customers." International Food and Agribusiness Management Review 14(4): 105-126.

Salois, M.J. 2012. "Obesity and Diabetes, the Built Environment, and the 'Local' Food Economy in the United States." Economics \& Human Biology 10(1): 35-42.

Schaumans, C. and F. Verboven, 2008. "Entry and Regulation: Evidence from Health Care Professions." RAND Journal of Economics 39(4): 949-972.

Schmidt, T. M. and M.I. Gómez. 2011. "Developing Viable Farmers Markets in Rural Communities: An Investigation of Vendor Performance Using Objective and Subjective Valuations." Food Policy 36(2): 119-127.

Seim, K. 2006. "An Empirical Model of Firm Entry with Endogenous Product-type Choices. RAND Journal of Economics" 37(3): 619-640.

Singleton, C. R., B. Sen and O. Affuso. 2015. "Disparities in the Availability of Farmers Markets in the United States." Environmental Justice 8(4): 135-143.

Stephenson, G., L. Lev and L. Brewer. 2008. 'I'm Getting Desperate': What We Know about Farmers' Markets that Fail. Renewable Agriculture and Food Systems 23(3), 188-200.

Varner, T. and D. Otto, 2008. "Factors Affecting Sales at Farmers' Markets: An Iowa Study." Review of Agricultural Economics 30(1): 176-189.

Thilmany, D., N. McKenney, D. Mushinski and S. Weiler. 2005. "Beggar-Thy-Neighbor Economic Development: A Note on the Effect of Geographic Interdependencies in Rural Areas." Annals of Regional Science 39(3): 593-605.

Wang, X. and K. M. Kockelman 2009. "Bayesian Inference for Ordered Response Data with a Dynamic Probit Model." Journal of Regional Science 49(5): 877-913.

Williams, R. 2006. "Generalized Ordered Logit/Partial Proportional Odds Models for Ordinal Dependent Variables." The Stata Journal 6(1): 58-82.

Wolf, M.M., A. Spittler and J. Ahern. 2005. "A Profile of Farmers' Market Consumers and the Perceived Advantages of Produce Sold at Farmers' Markets." Journal of Food Distribution Research 36(1): 192-201.

United States Department of Agriculture. 2012 "USDA Directory Records More Than 7,800 Farmers Markets. Release No. 0262.12. Available at http://www.usda.gov/wps/portal/ usda/usdahome?contentid=2012/08/0262.xml (accessed January 2016).

Zepeda, L. 2009. "Which Little Piggy Goes to Market? Characteristics of US Farmers' Market Shoppers." International Journal of Consumer Studies 33(3): 250-257. 